\title{
Lysine 63 ubiquitination is involved in the progression of tubular damage in diabetic nephropathy
}

\author{
Paola Pontrelli, ${ }^{*, 1}$ Francesca Conserva, ${ }^{,+}{ }^{+, 2}$ Massimo Papale, ${ }^{\ddagger, 2}$ Annarita Oranger, ${ }^{*}$ Mariagrazia Barozzino, ${ }^{*}$ \\ Grazia Vocino, ${ }^{*}$ Maria Teresa Rocchetti, ${ }^{*}$ Margherita Gigante, ${ }^{*}$ Giuseppe Castellano, ${ }^{*}$ Michele Rossini, ${ }^{*}$ \\ Simona Simone, ${ }^{*}$ Luigi Laviola, ${ }^{\S}$ Francesco Giorgino, ${ }^{\S}$ Giuseppe Grandaliano, ${ }^{\ddagger}$ Salvatore Di Paolo, ${ }^{\top}$ \\ and Loreto Gesualdo* \\ *Division of Nephrology, Dialysis, and Transplantation and ${ }^{\S}$ Division of Endocrinology, Department of Emergency and Organ Transplantation, \\ University of Bari, Bari, Italy; ${ }^{\dagger}$ Department of Cardiology and Cardiac Rehabilitation, Scientific Clinical Institute of Maugeri, Bari, Italy; ${ }^{\ddagger}$ Division \\ of Nephrology, Department of Medical and Surgical Sciences, University of Foggia, Foggia, Italy; and, ${ }^{\mathbb{N}}$ Nephrology Unit, Dimiccoli Hospital, \\ Barletta, Italy
}

\begin{abstract}
The purpose of our study was to evaluate how hyperglycemia (HG) influences Lys63 protein ubiquitination and its involvement in tubular damage and fibrosis in diabetic nephropathy (DN). Gene and protein expression of UBE2v1, a ubiquitin-conjugating E2-enzyme variant that mediates Lys63-linked ubiquitination, and Lys63ubiquitinated proteins increased in HK2 tubular cells under HG. Matrix-assisted laser desorption/ionization-time of flight/tandem mass spectrometry identified 30 Lys63-ubiquitinated proteins, mainly involved in cellular organization, such as $\beta$-actin, whose Lys63 ubiquitination increased under HG, leading to cytoskeleton disorganization. This effect was reversed by the inhibitor of the Ubc13/UBE2v1 complex NSC697923. Western blot analysis confirmed that UBE2v1 silencing in HK2 under HG, restored Lys63- $\beta$-actin ubiquitination levels to the basal condition. Immunohistochemistry on patients with type 2 diabetic (T2D) revealed an increase in UBE2v1- and Lys63-ubiquitinated proteins, particularly in kidneys of patients with DN compared with control kidneys and other nondiabetic renal diseases, such as membranous nephropathy. Increased Lys63 ubiquitination both in vivo in patients with DN and in vitro, correlated with $\alpha$-SMA expression, whereas UBE2v1 silencing reduced HG-induced $\alpha$-SMA protein levels, returning them to basal expression. In conclusion, UBE2v1- and Lys63-ubiquitinated proteins increase in vitro under HG, as well as in vivo in T2D, is augmented in patients with $\mathrm{DN}$, and may affect cytoskeleton organization and influence epithelial-to-mesenchymal transition. This process may drive the progression of tubular damage and interstitial fibrosis in patients with DN.Pontrelli, P., Conserva, F., Papale, M., Oranger, A., Barozzino, M., Vocino, G., Rochetti, M. T., Gigante, M., Castellano, G., Rossini, M., Simone, S., Laviola, L., Giorgino, F., Grandaliano, G., Di Paolo, S., Gesualdo, L. Lysine 63 ubiquitination is involved in the progression of tubular damage in diabetic nephropathy. FASEB J. 31, 308-319 (2017). www.fasebj.org
\end{abstract}

KEY WORDS: diabetic kidney $\cdot$ EMT $\cdot$ hyperglycemia $\cdot$ post-translational modifications

Diabetic nephropathy (DN) is the leading cause of end-stage renal disease. About one-third of patients with type 2 diabetes (T2D) develop this complication, which is characterized by distinctive changes in all renal compartments (1). Although it has been widely accepted that glomerular injury

ABBREVIATIONS: $\alpha$-SMA, $\alpha$-smooth muscle actin; DN, diabetic nephropathy; ECM, extracellular matrix; EMT, epithelial to mesenchymal transition; GBM, glomerular basal membrane; HG, hyperglycemia, hyperglycemic; HRP, horseradish peroxidase; MALDI-TOF/MS-MS, matrix-assisted laser desorption/ionization-time of flight/tandem mass spectrometry; MN, membranous nephropathy; PMF, peptide mass fingerprinting; siRNA, small interfering RNA; T2D, type 2 diabetes; UBE2v1, ubiquitinconjugating E2 enzyme variant 1

${ }^{1}$ Correspondence: Division of Nephrology, Dialysis and Transplantation, Department of Emergency and Transplantation, University of Bari, Piazza Giulio Cesare 11,70124, Bari, Italy. E-mail: paola.pontrelli@uniba.it ${ }^{2}$ These authors contributed equally to this work.

doi: $10.1096 /$ fj.201600382RR is the main component of $\mathrm{DN}$, tubular-interstitial changes have been reported to be involved in its progression (2).

A typical DN histologic signature is extracellular matrix (ECM) deposition, both in the glomerulus and in the tubular-interstitial compartment, and it is mainly responsible for the progression of interstitial fibrosis and glomerulosclerosis (3).

Epithelial-to-mesenchymal transition (EMT) represents the process in which tubular epithelial cells start to express fibroblast markers and thus play a role in the progression of kidney fibrosis (4). Its involvement in the progression of tubular-interstitial fibrosis is controversial; however, it has been found that EMT represents the principal source of myofibroblasts in DN (5).

Development and progression of DN are significantly greater in patients with poor glycemic control; therefore, high glucose toxicity has been suggested as a major cause of renal damage (6). Several pathways are activated in 
response to hyperglycemia (HG) (7-9); however, the molecular mechanisms underlying tubular damage by HG are still largely unclear.

The ubiquitin pathway is emerging as a possible key player in the onset of DN (10-12). Our group identified free ubiquitin as a potential biomarker in urine samples of patients with DN compared to patients with diabetes who have other chronic kidney diseases (13). Moreover, Dihazi et al. (14) reported the presence of the ubiquitin fusion protein $\mathrm{UbA52}$ in urine of patients with $\mathrm{T} 2 \mathrm{D}$ with macroor microalbuminuria, suggesting its role as a tubular injury indicator. In the kidney, UbA52 was exclusively located in tubules, and its expression in mouse kidney was found to be proportional to the glucose concentrations in blood (15).

Ubiquitination is a fundamental process in intracellular signaling, as it controls numerous aspects of protein function (16). Ubiquitination is a multistep process, consisting of the attachment of the 8-kDa ubiquitin moiety to target proteins after sequential action of 3 classes of enzymes: an E1 ubiquitin-activating enzyme, an E2 ubiquitin-conjugating enzyme, and an E3 ubiquitin ligase (17). E2 is responsible both for E3 selection and substrate modification; thus, E2s function at the heart of the ubiquitin transfer pathway and are responsible for much of the diversity of ubiquitin cellular signaling (18).

Polyubiquitin chain formation occurs when a Lys residue of ubiquitin is linked to the C-terminal glycine of another ubiquitin; substrate proteins can be linked to ubiquitin using 7 distinct ubiquitin Lys residues (Lys6, -11, -27, -29, -33, -48, and 63). The different bound Lys-residue of the polyubiquitin chain targets proteins to different fates $(19,20)$. The Lys63 modification in particular is not responsible for protein degradation, but affects protein localization and cell signaling, thus regulating protein function and scaffolding interactions, such as in NF-кB activation $(21,22)$.

The ubiquitin-conjugating E2 enzyme variant 1 , UBE2v1, also called UEV1 or MMS2, is a cofactor of UBC13, the only known E2 Ub-conjugating enzyme that produces Lys63-linked ubiquitin chain, and represents a distinctive group among the E2 protein family that maintains the enzymatic core of ubiquitin-conjugating enzymes but lacks a conserved cysteine residue with catalytic activity (23).

The involvement of UBE2v1 in diabetes has only been hypothesized. Woroniecka et al. (9) reported an increased UBE2v1 gene expression in microdissected tubules of human DN kidneys compared with healthy control kidneys. Moreover, this gene maps on chromosome 20, where T2D candidate risk genes are concentrated (24). The possible connection of Lys63 protein ubiquitination in T2D and subsequent renal damage has not been explored so far.

Thus, the purpose of our study was to evaluate the role of Lys63 protein ubiquitination in response to HG and its possible involvement in the progression of tubular damage and fibrosis in $\mathrm{DN}$.

\section{MATERIALS AND METHODS}

\section{Reagents}

Anti-UBE2v1, anti- $\beta$-actin, anti-ubiquitin, and anti- $\alpha$ smooth muscle actin ( $\alpha$-SMA) antibodies were from Abcam (Cambridge, United
Kingdom). Anti-ubiquitin Lys63-specific antibody was from Merck Millipore (Darmstadt, Germany). Horseradish peroxidase (HRP)conjugated antibodies were supplied by Santa Cruz (Dallas, TX, USA). The selective inhibitor of the Ubc13/Uev1A (UBE2v1) complex, NSC697923 (25), was from Selleckchem (Houston, TX, USA). All other chemicals were reagent grade.

\section{Cell culture}

$\mathrm{HK} 2$, an immortalized proximal tubular epithelial cell line from normal adult human kidney (26), was from American Type Culture Collection (Rockville, MD, USA). Cells were grown in DMEM with $1000 \mathrm{mg}$ glucose/L (low glucose: $5.5 \mathrm{mM}$ ) supplemented with $10 \%$ fetal bovine serum, $100 \mathrm{U} / \mathrm{ml}$ penicillin, $100 \mu \mathrm{g} / \mathrm{ml}$ streptomycin, and $2 \mathrm{mM}$ L-glutamine (SigmaAldrich, St. Louis, MO, USA) (complete medium). This condition was regarded as basal. For passage, confluent cells were washed with PBS, removed with $0.5 \%$ trypsin $/ 0.02 \%$ EDTA in PBS and plated in complete medium with or without $24.5 \mathrm{mM}$ D-glucose or L-glucose, the L-isomer of glucose, as osmolarity control, for the indicated times.

\section{Western blot analysis}

Cells were lysed in RIPA buffer [5 mM EDTA, $1 \mathrm{mM}$ sodium orthovanadate, $150 \mathrm{mM}$ sodium chloride, $1.5 \%$ Nonidet P-40, $20 \mathrm{mM}$ Tris- $\mathrm{HCl}$ ( $\mathrm{pH} 7.4$ ), $10 \mu \mathrm{l} / \mathrm{ml}$ 2-chloroacetamide, and $10 \mu \mathrm{l} / \mathrm{ml}$ phosphatase inhibitor cocktail]. Proteins $(40 \mu \mathrm{g})$ from each lysate underwent SDS/PAGE on a $4-15 \%$ precast polyacrylamide gel (Bio-Rad, Milan, Italy) and then were electrotransferred onto $0.2 \mu \mathrm{m}$ PVDF membrane. The filter was blocked with $5 \%$ skim milk powder in TBS $(1 \times$ PBS $+0.1 \%$ Tween- 20$)$ and then incubated with the anti-UBE2v1 or the anti-ubiquitin, Lys63-specific antibody or, in separate sets of experiments, with the anti- $\alpha$-SMA antibody. Membranes were incubated with the appropriate HRP-conjugated secondary antibody, stripped, and immunoblotted again with anti- $\beta$ actin antibody. The ECL enhanced chemiluminescence system was used for detection (GE Healthcare Life Sciences, Milan, Italy). Quantification of band intensities was performed by the function "Analyze and Label peaks" of the ImageJ 1.34 Software (National Institutes of Health, Bethesda, MD, USA; http://rsb.info.nih.gov/ij/).

\section{UBE2v1 silencing and immunoprecipitation}

UBE2v1 silencing was performed according to the manufacturer's instruction by the transfection of 4 preselected small interfering RNAs (siRNAs) $(1 \mathrm{nmol})$ for the target gene (FlexiTube GeneSolution; Qiagen, Hilden, Germany) with TransIT-TKO Transfection Reagent (Mirus Bio, Madison, WI, USA) in HK2 cells. All-Star control siRNA (Qiagen) was used as the vital scrambled control.

Immunoprecipitation on protein extracts was performed with the IP-50 Protein G Immunoprecipitation kit (Sigma-Aldrich). In brief, $200 \mu \mathrm{g}$ of proteins was incubated with the anti- $\beta$ actin antibody, for $3 \mathrm{~h}$ on a rocking platform at $4^{\circ} \mathrm{C}$, and then with protein $\mathrm{G}$ Sepharose overnight at $4^{\circ} \mathrm{C}$. Immunoprecipitated proteins were eluted in sample buffer [2-ME, 10\% SDS, $10 \%$ glycerol, $0.5 \mathrm{M}$ Tris- $\mathrm{HCl}$ (pH 6.8), and $0.05 \%$ bromophenol blue], boiled, and subjected to SDS-PAGE.

\section{Isolation and identification of ubiquitinated proteins}

Pierce Crosslink IP Kit (ThermoFisher Scientific, Rodano, Italy) with a specific anti-ubiquitin antibody was used to purify 
ubiquitinated proteins. In brief, samples were precleared by incubating $500 \mu \mathrm{g}$ of proteins with protein $\mathrm{G}$ agarose resin. Ubiquitin antibody was then added to $200 \mu$ l of protein $G$ agarose resin and covalently immobilized by crosslinking with disuccinimidyl suberate (DSS). The antibody resin was incubated with $500 \mu \mathrm{g}$ of total protein extracts of $\mathrm{HK} 2$ cells. After washing, ubiquitinated proteins were eluted in $40 \mu \mathrm{l}$ elution buffer [UREA 9M, 3-[(3-cholamidopropyl)dimethylammonio]1-propanesulfonate (CHAPS) $2 \%$, and DTT $100 \mathrm{mM}$ ] and subjected, in duplicate, to SDS/PAGE on a $12 \%$ homemade polyacrylamide gel. One gel duplicate underwent immunoblot analysis with anti-ubiquitin, Lys63-specific antibody as previously described, while the other was stained by colloidal Coomassie Blue G-250. Gel destaining was achieved by sequential washing until protein bands were clearly visible. Coomassie-stained gel and ubiquitin-Lys63-immunoblotted membranes were compared to select, among all the immunoprecipitated proteins, the Lys63-ubiquitinated ones. Bands of interest were excised and trypsin digested according to our optimized protocol (27). Eluted peptides were analyzed by matrix-assisted laser desorption/ionization-time of flight/ tandem mass spectrometry (MALDI-TOF/MS-MS).

\section{MALDI-TOF/MS-MS}

A peptide mixture of the selected protein bands was separately loaded on a prespotted anchor chip (Bruker Daltonics, Bremen, Germany). MS and MS/MS analyses were performed on an Autoflex IIITOF/TOF200 instrument (Bruker Daltonics) (27). Protein identification was performed on NCBInr and Swissprot databases with the Mascot search algorithm (Matrix Science, Boston, MA, USA; http://www.matrixscience.com/), with the following parameters: Homo sapiens (taxonomic category), trypsin (enzyme), carbamidomethyl (fixed modification for cysteine residues), and oxidation of methionine (variable modification). Mass tolerance was 100 for the monoisotopic peptide masses and 0.3 Da for MS/MS analysis. Confident identification of proteins was achieved when the threshold significance score exceeded $56(P<0.05)$ for peptide mass fingerprinting $(\mathrm{PMF})$ and $27(P<0.05)$ for MS/MS data.

Ubiquitin remnant-containing peptides (28) were identified by searching for the ubiquitin signature (GG, 114.05 Da, or LRGG, 383.23 Da) linked to a Lys residue of the predicted tryptic peptides.

Functional analysis of the identified proteins was obtained through Ingenuity Pathway Analysis (IPA; Qiagen).

\section{RNA isolation and real-time PCR}

Total RNA was extracted with TRI Reagent (Sigma-Aldrich). RNA concentration and purity was assessed by the NanoDrop ND-1000 Spectrophotometer (ThermoFisher Scientific). Reverse transcription of total RNA was performed using the High Capacity cDNA Reverse Transcription Kit (ThermoFisher Scientific). SYBR-green quantitative PCR amplification was performed in triplicate using specific primers for UBE2v1 (forward: TGGAGTGGTGGACCCAAGA; reverse: TAACACTGTCCTTCGGGCG); data were analyzed with the Light Cycler 96 thermal cycler software SW 1.1 (Roche Diagnostics, Monza, Italy).

\section{Confocal microscopy}

$\beta$-Actin cell distribution, Lys63 ubiquitination, and $\alpha$-SMA expression were evaluated in HK2 cells and tissues, by indirect immunofluorescence and confocal microscopy analysis. Cells $\left(5 \times 10^{4}\right)$ were plated on a coverslip and incubated with $30 \mathrm{mM} \mathrm{D}-$ or L-glucose for various times. NSC697923 inhibitor $(1 \mu \mathrm{M})$ was preincubated for $1 \mathrm{~h}$ before adding D-glucose. HK2 cells were then fixed with $4 \%$ paraformaldehyde, treated with $0.2 \%$ TritonX 100/PBS, and incubated in blocking buffer (4\% goat serum, $2 \%$ bovine serum albumin/PBS) and then with the anti-ubiquitin, Lys63-specific antibody or anti- $\alpha$-SMA antibody.

Immune complexes were identified by incubating cells with the secondary antibody (Alexa Fluor 555 or Alexa Fluor 488; ThermoFisher Scientific). In some experiments after incubation with the anti-ubiquitin, Lys63-specific antibody, and Alexa Fluor 555 , the anti- $\beta$-actin antibody was added and detected by the Alexa Fluor 488 goat anti-mouse antibody.

Renal biopsies were deparaffinized and subjected to $3 \mathrm{mi}-$ crowave $(750 \mathrm{~W})$ cycles of $5 \mathrm{~min}$ in citrate buffer (pH6) to unmask the epitope. The slides were then incubated with the appropriate blocking solution, primary antibodies (anti- $\alpha$-SMA 1:100, antiubiquitin, Lys63-specific antibody 1:50) and the appropriate secondary antibodies (Alexa Fluor 488 and 555).

Samples were counterstained with TO-PRO-3 (ThermoFisher Scientific), mounted in Fluoromount (Vector Laboratories, Burlingame, CA, USA), and sealed. Negative control was obtained omitting the primary antibodies.

Cell-specific fluorescence was analyzed by confocal laser scanning microscopy with the TCSSP2 (Leica, Wetzlar, Germany), equipped with argon-krypton (488 nm), green neon (543 nm), and helium neon $(633 \mathrm{~nm})$ lasers. Images were recorded with the Leica imaging software.

\section{Kidney samples and immunohistochemistry}

Kidney samples were obtained by needle-core biopsies, fixed in $4 \%$ formaldehyde, and processed for routine histologic staining (hematoxylin-eosin, periodic acid-Schiff, silver methenamine, and Masson's trichrome). The histologic lesions and the extent of interstitial fibrosis were scored independently by 2 pathologists (ADP, MR) blinded to the clinical history of the patient assigning a score ranging from +: $0-30 \%$ (minimal fibrosis), to +++ : 60-100\% (completely fibrotic). For immunohistochemistry we used the remaining portions of kidney biopsies from 4 subjects screened as potential kidney donors for transplantation with T2D without any histologic and clinical evidence of renal damage; 9 patients with T2D and biopsy-proven diagnosis of DN, from 4 controls with urinary abnormalities (hematuria and proteinuria of $\leq 1 \mathrm{~g} / 24 \mathrm{~h}$ ) undergoing kidney biopsy; and 4 patients with biopsy-proven diagnosis of membranous nephropathy (MN). Patients with DN were characterized by mesangial proliferation and ECM accumulation in the glomeruli, podocyte loss, glomerular basal membrane (GBM) thickening, and a mild vacuolar degradation of tubular cells in the presence of focal tubular atrophy and classified as class III in accordance with Tervaert et al (29). Controls showed a normal kidney, at both optical and electron microscopy examination. Patients with idiopathic MN presented the classic histologic features (GBM thickening with granular IgG deposits). The study was conducted according to the latest version of the Declaration of Helsinki and was approved by the local ethics committee (Prot. N.4104/2013). The main demographics and clinical characteristics of the patients enrolled are reported in Table 1.

For the immunohistochemical evaluation of UBE2v1 protein expression and Lys63-ubiquitinated protein accumulation, $4 \mu \mathrm{m}$ thick sections of paraffin-embedded tissue after rehydration and antigenic retrieval were incubated with $\mathrm{H}_{2} \mathrm{O}_{2}(3 \%)$ and then with Triton $(0.25 \%)$. After blocking with protein block (Dako, Glostrup, Denmark), sections were incubated with anti-UBE2v1 or antiubiquitin, Lys63-specific antibody in a humidified chamber. The immune complexes were detected by the peroxidase/DAB Dako Real EnVision Detection System (Dako). The peroxidase reaction was shown by a brown precipitate, counterstained with Mayer's hematoxylin (blue) and mounted with glycerol (DakoCytomation, 


\begin{tabular}{|c|c|c|c|c|}
\hline Clinical characteristic & Control & Diabetic & $\begin{array}{c}\text { Diabetic nephropathy: } \\
\text { class III }\end{array}$ & $\begin{array}{l}\text { Membranous } \\
\text { nephropathy }\end{array}$ \\
\hline Patients $(n)$ & 4 & 4 & 9 & 4 \\
\hline $\operatorname{Sex}(M / F)$ & $2 / 2$ & $2 / 2$ & $5 / 4$ & $4 / 0$ \\
\hline Age (yr) & $48 \pm 14$ & $64 \pm 8.3$ & $68 \pm 3.1$ & $52 \pm 17.2$ \\
\hline Blood pressure $(\mathrm{mmHg})$ & $123 \pm 9 / 75 \pm 5$ & $117 \pm 9 / 62 \pm 16$ & $135 \pm 13 / 75 \pm 5.8$ & $133 \pm 25 ; 82 \pm 16$ \\
\hline Serum creatinine & $0.8 \pm 0.1$ & $0.9 \pm 0.2$ & $2.1 \pm 0.7$ & $1.3 \pm 0.6$ \\
\hline Proteinuria (g/24 h) & $0.04 \pm 0.02$ & $0.8 \pm 0.2$ & $2.5 \pm 1.7$ & $7.1 \pm 3.5$ \\
\hline $\begin{array}{l}\text { Estimated glomerular } \\
\text { filtration rate }(\mathrm{ml} / \mathrm{min})\end{array}$ & $80 \pm 10$ & $75 \pm 45$ & $45 \pm 20$ & $78 \pm 42$ \\
\hline Body mass index & $26 \pm 4.4$ & $32 \pm 11$ & $30 \pm 4.3$ & $30 \pm 4$ \\
\hline Glycosylated hemoglobin (\%) & $5.1 \pm 0.1$ & $7.7 \pm 0.9$ & $9.7 \pm 0.9$ & $5.1 \pm 0.9$ \\
\hline
\end{tabular}

Carpinteria, CA, USA). Negative controls were obtained by omitting the primary antibody. Digital images were acquired at $\times 20$ magnification, using the ScanScope CS2 device (Aperio Technologies, Vista, CA, USA) and analyzed by ImageScope V12.1.0.5029 (Aperio Technologies). Specific staining was quantified using the Positive Pixel Count v9_v10.0.0.1805 algorithm (Aperio Technologies) to measure the number of positive cells. For each region (high-power field; hpf) the number of cells with strong $(3+)$ signal identified by the algorithm was considered.

\section{Statistical analysis}

Data are presented as means $\pm \mathrm{SD}$ and compared by unpaired Student's $t$ test. A value of $P<0.05$ indicated statistical significance.

\section{RESULTS}

\section{UBE2v1 expression and Lys63 protein ubiquitination increase in tubular cells under HG conditions}

We first investigated whether HG could alter UBE2v1 gene expression and subsequent Lys63 ubiquitination of targeted proteins in vitro. We observed a rapid increase in UBE2v1 gene expression by real-time PCR in HK2 cells under HG (compared to L-glucose), with the peak occurring after $1 \mathrm{~h}$ of incubation (Fig. $\mathbf{1 A}$ ). The rapid increase in gene expression, was also associated with an increase in protein production, because, in HG conditions, both
A

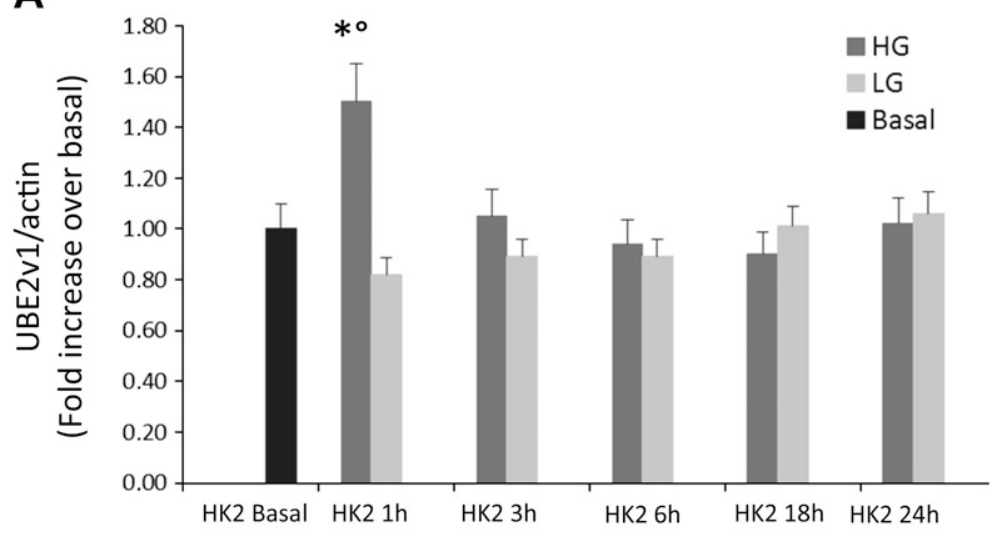

B

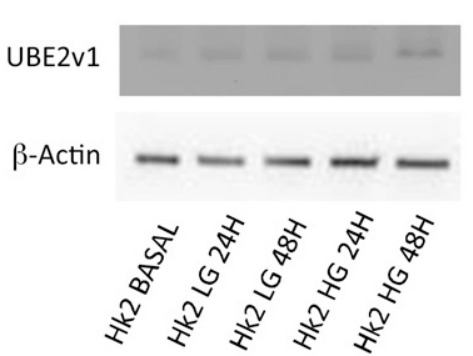

C
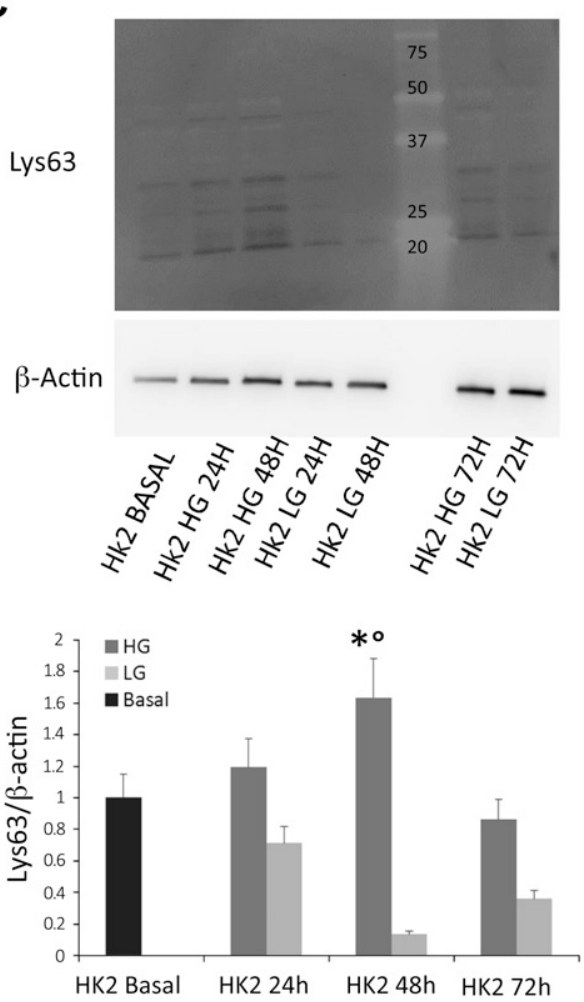

Figure 1. Effect of high glucose on UBE2v1 gene $(A)$ and protein expression $(B)$ and Lys63 protein ubiquitination $(C)$ in tubular cells. A) UBE2v1 gene expression was evaluated by quantitative PCR. B) Left: UBE2v1 protein levels in HK2 cells, normalized to $\beta$-actin expression. Right: quantification of UBE2v1 protein expression in 3 independent experiments. C) Top: Lys63 ubiquitination in HK2 cells normalized to $\beta$-actin expression. Bottom: quantification of Lys63-ubiquitinated proteins normalized to $\beta$-actin expression. Each experiment was performed at least 3 times. Histogram data are means \pm SD. $* P<0.05$ vs. basal; ${ }^{\circ} P<0.05$ vs. LG. 
UBE2v1 (Fig. 1B) and Lys63-ubiquitinated proteins (Fig. 1C) rose, with a peak $48 \mathrm{~h}$ after incubation.

\section{Identification of Lys63-ubiquitinated proteins in tubular cells under HG conditions}

To identify those proteins undergoing HG-mediated Lys63 ubiquitination and their potential role in driving the progression of tubular damage in patients with diabetes, a MALDI-TOF/MS-MS analysis was used. For this purpose, HK2 cells were incubated for $48 \mathrm{~h}$ with $30 \mathrm{mM}$ D- or L-glucose, and, after immunoprecipitation of total ubiquitinated proteins, they were separated by monodimensional SDS gel electrophoresis and identified by MALDI-TOF/MS-MS, as described in Materials and Methods. We recognized 30 proteins among those showing increased Lys63 ubiquitination after HG stimulation (Table 2). To better understand their functional role and the biological pathways in which these proteins were involved, we used the IPA software. It recognized 14 proteins included in a unique functional network, and all such proteins were linked to ubiquitin $C$, a polyubiquitin precursor, thus supporting the role of ubiquitination in the functional modulation of the identified proteins (Fig. 2). The identified proteins were mostly involved in the regulation of cell morphology and structure, and almost all networks screened included $\beta$-actin and G1-actin (Table 3). MS-MS analysis of the predicted $\beta$-actin-ubiquitinated peptide enabled identification of Lys328 as a potential target site for Lys63 ubiquitination (Fig. 3).

\section{HG-induced Lys63 ubiquitination affects actin organization}

To confirm Lys63 actin ubiquitination and to evaluate the role of this process in tubular damage leading to $\mathrm{DN}$, we performed a confocal analysis of $\beta$-actin Lys63 ubiquitination, in HK2 under HG. Whereas in basal conditions or after exposure to high levels of L-glucose, Lys63ubiquitinated proteins were mainly concentrated in the perinuclear area, and actin fibers appeared well organized, actin fibers lost their typical organization and were totally ubiquitinated in Lys63 under HG (Fig. 4A). Selective inhibition of the Ubc13-Uev1A complex by NSC697923 restored basal $\beta$-actin organization, also under HG. To confirm the specific Lys63 ubiquitination of actin fibers, we performed immunoprecipitation of $\beta$-actin proteins in HK2 cells. The amount of $\beta$-actin with Lys63-specific ubiquitination in HG was significantly higher after $48 \mathrm{~h}$, when compared to both basal conditions and L-glucose

TABLE 2. Anti-ubiquitin-Lys63 immunoprecipitated proteins identified by MALDI-TOF-MS/MS analysis

\begin{tabular}{|c|c|c|c|c|}
\hline Gel band & Protein & Uniprot accession no. & Mascot score & $\begin{array}{l}\text { Peptide, } \\
\text { MS/MS }(n)\end{array}$ \\
\hline 2 & $\beta$-Actin, cytoplasmic 1 , partial & P60709 & 122 & 6 \\
\hline 2 & $\beta$-Actin variant & Q53G99 & 122 & 5 \\
\hline 3 & Actin, cytoplasmic 2, partial & $\widetilde{\mathrm{P}} 63261$ & 122 & 5 \\
\hline 3 & Ubiquitin-conjugating enzyme $\mathrm{E} 2 \mathrm{~W}$ isoform 1 & Q96B02 & 56 & 1 \\
\hline 3 & ACTG1 protein, partial (Homo sapiens) & $\widetilde{P} 63261$ & 99 & 6 \\
\hline 6 & $\alpha$-Enolase & P06733 & 70 & 4 \\
\hline 10 & Chain A, pyruvate kinase & Q504U3 & 101 & 3 \\
\hline 10 & ZBTB44 protein & Q8NCP5 & 74 & 2 \\
\hline 11 & Selenocysteine-specific elongation factor & $\mathrm{P} 57772$ & 72 & 2 \\
\hline 12 & Chain A, structure of human transketolase & P29401 & 96 & 2 \\
\hline 19 & 5-Aminolevulinate synthase, erythroid-specific, mitochondrial & $\mathrm{P} 22557$ & 68 & 3 \\
\hline 19 & E3 Ubiquitin protein ligase & Q96PU4 & 63 & 5 \\
\hline 19 & $\gamma$-Aminobutyric acid receptor subunit $\beta-3$ & P28472 & 62 & 2 \\
\hline 19 & Holliday junction recognition protein & Q8NCD3 & 89 & 2 \\
\hline 19 & Protein FAM217B & Q9NTX9 & 62 & 2 \\
\hline 19 & RILP-like protein 1 & Q5EBL4 & 63 & 2 \\
\hline 19 & RUN and FYVE domain-containing protein 4 & Q96T51 & 75 & 1 \\
\hline 19 & SHC SH2 domain-binding protein 1-like protein & $\widetilde{Q} 9 B Z Q 2$ & 72 & 4 \\
\hline 19 & Translocating chain-associated membrane protein 1 & $\widetilde{Q} 15629$ & 63 & 1 \\
\hline 19 & Tropomodulin-4 & Q9NZQ9 & 66 & 2 \\
\hline 19 & UPF0704 protein C6orf165 & Q8IYR0 & 72 & 3 \\
\hline 19 & WW domain-binding protein 4 & $\widetilde{O} 75554$ & 68 & 1 \\
\hline 19 & P2X purinoceptor 5 & Q93086 & 64 & 1 \\
\hline 19 & Synaptotagmin-like protein 2 (isoform 2) & $\widetilde{Q} 9 \mathrm{HCH5-2}$ & 66 & 4 \\
\hline 22 & Core-binding factor, runt domain, $\alpha$-subunit 2 ; translocated to, 2 & $\widetilde{\mathrm{O}} 43439$ & 71 & 1 \\
\hline 22 & Semaphorin-4D & Q92854 & 59 & 1 \\
\hline 23 & Glutamate-rich protein 6 & Q7L0X2 & 67 & 1 \\
\hline 25 & SPARC-related modular calcium-binding protein 2 & Q9H3U7 & 58 & 2 \\
\hline 28 & $\begin{array}{l}\text { Chain A, human Hsp90- } \beta \text { With Pu3 [9-butyl-8(3,4,5-trimethoxy- } \\
\text { benzyl)-9H-purin-6-ylamine] }\end{array}$ & $\widetilde{\mathrm{P} 08238}$ & 58 & 2 \\
\hline 30 & Protein FAM178A & Q8IX21 & 60 & 2 \\
\hline
\end{tabular}

Gel band numbers correspond to the rimmed band shown in Fig. 3. 


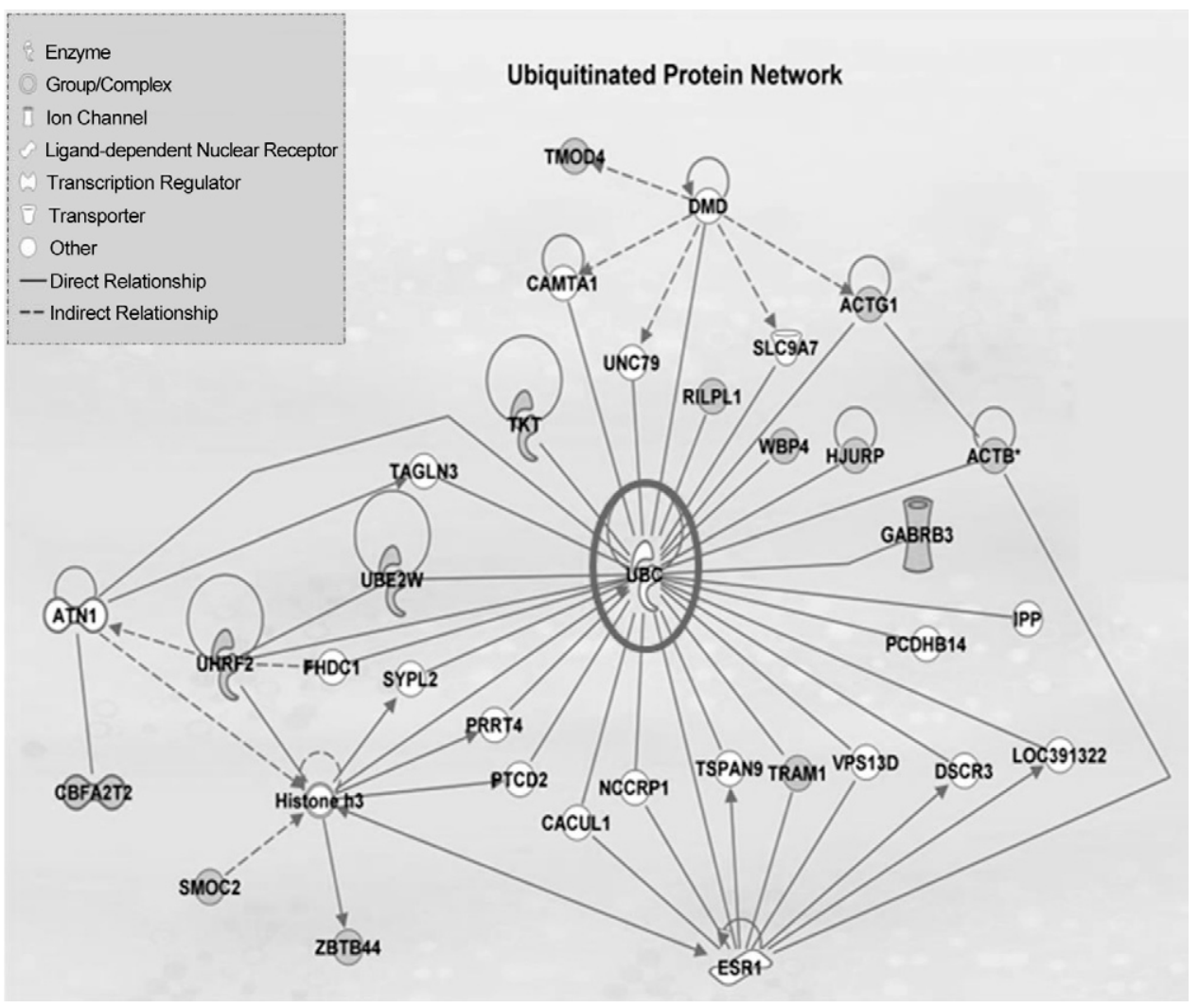

Figure 2. Functional analysis of Lys63-ubiquitinated proteins in HK2 cells under HG conditions. Ubiquitinated proteins were identified by MALDI-TOF/MS-MS (identified proteins are listed in Table 2) and functionally analyzed by the IPA software. The network, graphically represented as nodes (proteins) and edges (the biologic relationship between proteins), was constructed by IPA software. Colored nodes represent Lys63-ubiquitinated proteins in $\mathrm{HK} 2$ cells under $\mathrm{HG}$ conditions; others (empty nodes) are those that IPA automatically includes as biologically linked. Meanings of node shapes and edges are indicated in the legend within the figure. Table 3 displays the most significant molecular and cellular functions of the Lys63-ubiquitinated proteins under HG.

stimulation. This process was dependent on UBE2v1, in that its silencing completely blocked D-glucose-induced $\beta$-actin Lys63 ubiquitination (Fig. 4B, C).

\section{UBE2v1 expression and Lys63 protein ubiquitination in vivo in diabetes, with and without DN and other nondiabetic nephropathies}

To confirm whether HG conditions could be responsible for the increased Lys63 protein ubiquitination, we analyzed UBE2v1 protein expression and Lys63 ubiquitination in kidney biopsies of patients with T2D, with or without class III DN, compared with control kidneys and patients with $\mathrm{MN}$. Immunohistochemistry revealed that both UBE2v1 protein expression (Fig. $\mathbf{5 A}-\boldsymbol{F}$ ) and Lys63 protein ubiquitination (Fig. $5 H-M$ ) were completely absent in control kidneys (Fig. 5C, J) and in kidney biopsies of patients with proteinuric nephropathies and nondiabetic renal diseases, such as MN (Fig. 5F, M). By contrast, UBE2v1 protein expression and Lys63 ubiquitination, were instead significantly increased in patients with $\mathrm{T} 2 \mathrm{D}$ (Fig. 5A, B, H, I). Both signals were detected only at the tubular level and only in some tubules. The same pattern of UBE2v1 protein expression and of Lys63-ubiquitinated proteins increased in atrophic tubules of patients with DN (Fig. $5 D, E, K, L$ ), as demonstrated by quantification of UBE2v1 (Fig. 5O) and Lys63-ubiquitinated (Fig. 5P) proteins.

\section{Lys63 ubiquitination led to expression of mesenchymal markers by epithelial cells}

By transmission electron microscopy, we observed, in patients with DN compared to controls, focal epithelial necrosis of tubular lining cells, with a loss of cell-tobasement membrane adhesion. Epithelial cells of the proximal tubule were flattened with diminished brush border, loss of cellular adhesion, and reduced complexity of basolateral membrane folds (data not shown). One of the principal events leading to EMT is represented by reorganization of the cytoskeletal architecture, loss of

TABLE 3. Molecular and cellular functions of the Lys63 ubiquitinated proteins in HK2 cells under HG, identified by the IPA software

\begin{tabular}{lll}
\hline \hline Function & \multicolumn{1}{c}{$P$} & \multicolumn{1}{c}{ Symbol } \\
\hline Cell morphology & $7.53 \mathrm{E}^{-04}-2.75 \mathrm{E}^{-02}$ & ACTB, CBFA2T2, GABRB3 \\
Cellular function and maintenance & $1.31 \mathrm{E}^{-03}-2.68 \mathrm{E}^{-02}$ & ACTB, ACTG1, RILPL1 \\
Cell-to-cell signaling and interaction & $1.50 \mathrm{E}^{-03}-4.57 \mathrm{E}^{-02}$ & ACTB, ACTG1, GABRB3 \\
Carbohydrate metabolism & $1.51 \mathrm{E}^{-03}-6.01 \mathrm{E}^{-03}$ & TKT \\
Cellular assembly and organization & $1.51 \mathrm{E}^{-03}-3.12 \mathrm{E}^{-02}$ & ACTB, ACTG1, HJURP \\
\hline
\end{tabular}




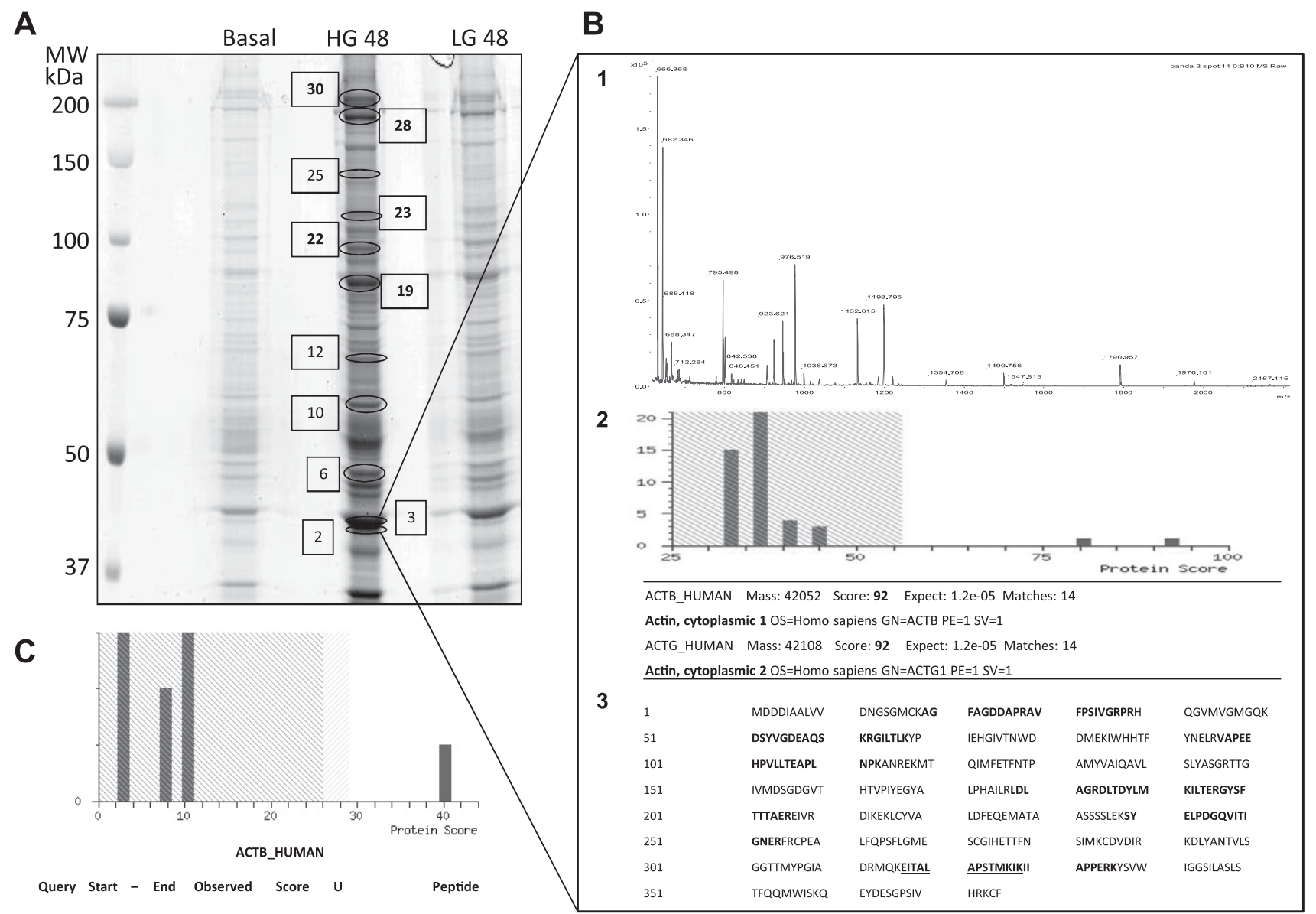

Figure 3. Identification of ubiquitinated $\beta$-actin by MALDI-TOF-MS/MS analysis. $A$ ) Monodimensional SDS gel electrophoresis of anti-ubiquitin immunoprecipitated proteins of $\mathrm{HK} 2$ cells in the indicated conditions. Rimmed bands have been analyzed by MALDI-TOF-MS/MS analysis. The numbered gel bands correspond to the number of the proteins identified in Table 2. B) PMF spectra of the gel bands (1) with the corresponding histogram of the Mascot score search result for MS analysis (2), and display of the relative entries, which identified $\beta$-actin; $\beta$-actin amino acid sequence (3) is shown with matched peptides in bold and the ubiquitinated peptide (+GG) underlined. $C$ ) Histogram of Mascot score search results for MS/MS sequencing and display of the $\beta$-actin-ubiquitinated peptide (aa 316-328+GG).

cellular polarity, and increased expression of markers defining the mesenchymal phenotype, such as $\alpha$-SMA. On this basis, we decided to investigate whether accumulation of Lys63-ubiquitinated proteins could induce expression of mesenchymal markers by epithelial cells in vivo. For this purpose, we analyzed $\alpha$-SMA expression and Lys63 ubiquitination by confocal microscopy on kidney biopsies of selected patients with class III DN, reporting different grades of interstitial fibrosis. We observed that patients with $\mathrm{DN}$ with a lesser extent of interstitial fibrosis (Fig. 6, DN + and ++), as defined by the Masson's trichrome staining (Fig. 6C), were characterized by the expression of $\alpha$-SMA marker in tubules characterized by the presence of Lys63-ubiquitinated proteins (Fig. 6A, B). Of note, the increase in the extent of interstitial fibrosis (Fig. 6, $\mathrm{DN}+++$ patients) inversely correlated with the presence of tubular cells positive for both Lys63-ubiquitinated proteins and $\alpha$-SMA, suggesting that fibroblasts have already induced scarring of kidney tissue.

In vitro, we also confirmed that Lys63 ubiquitination was responsible for increased $\alpha$-SMA expression, in that inhibition of Lys63 ubiquitination by NSC697923 inhibited $\alpha$-SMA expression induced by high glucose (Fig. $6 D$ ).

Because this observation suggested that EMT could be induced by deposition of Lys63-ubiquitinated proteins, thus promoting progression of fibrosis, we also evaluated the effect of UBE2v1 silencing in high glucose-induced $\alpha$-SMA expression in HK2 cells. HG induced a significant increase in $\alpha$-SMA expression with a peak after $48 \mathrm{~h}$ of incubation and this increase was completely abolished by UBE2V1 silencing (Fig. 6E, F).

\section{DISCUSSION}

In the present study, 1) HG increased UBE2v1 expression and Lys63 protein ubiquitination in cultured human tubular cells; 2) Lys63 ubiquitination targeted the proteins mainly involved in cell morphology and structure, such as $\beta$-actin and G1-actin; 3) HG-induced Lys63 ubiquitination of actin-modified cytoskeletal organization, and this effect was reversed by selective inhibition or silencing of 
A
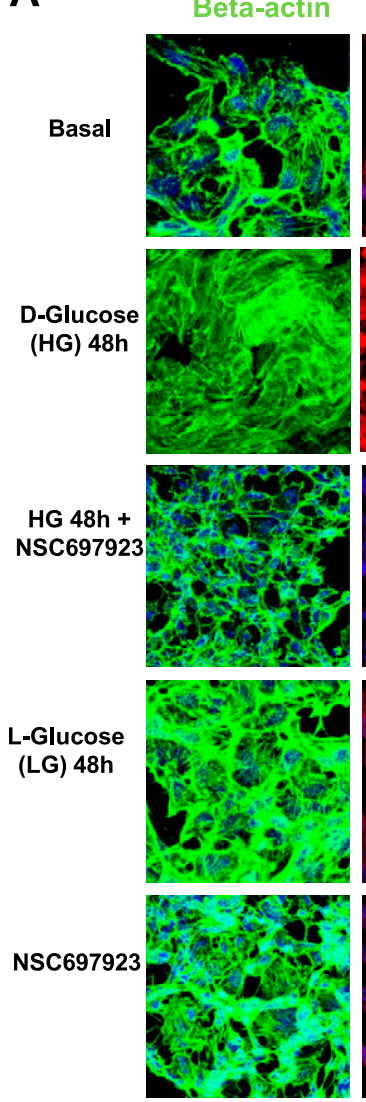

Lys63
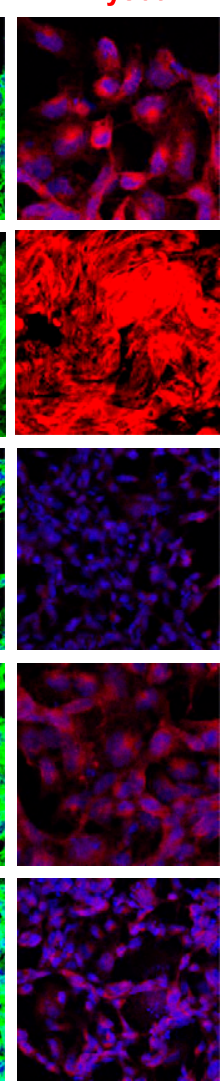

Overlay
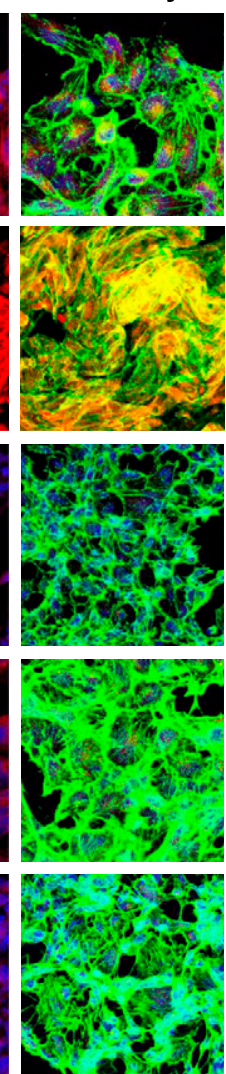

Zoom
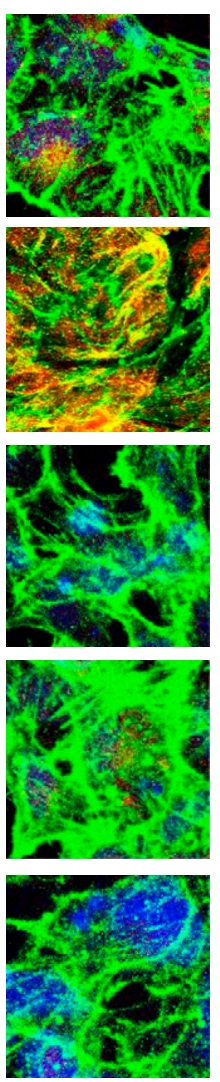

B

Lys63
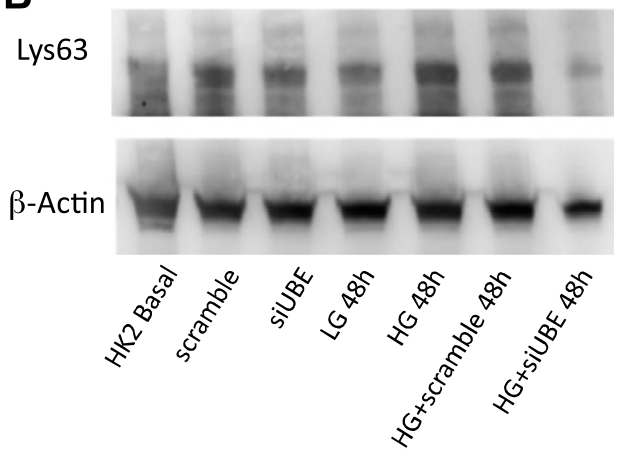

C

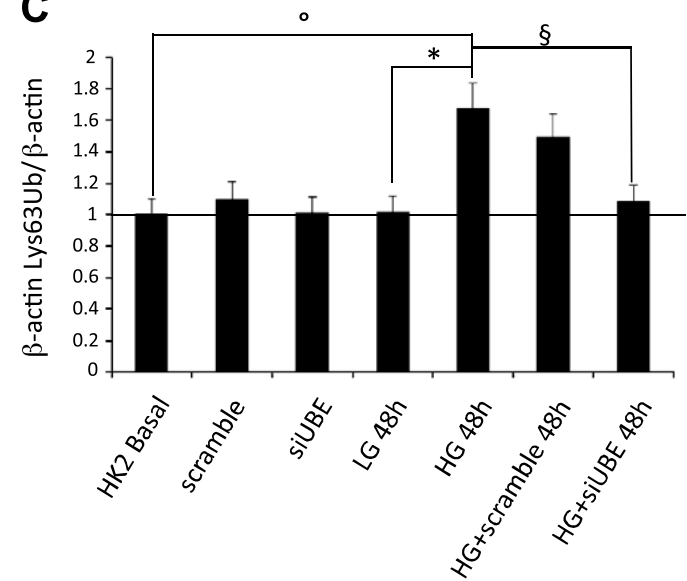

Figure 4. A) Immunofluorescence analysis of $\beta$-actin distribution and Lys63 ubiquitination in HK2 cells. Cells were preincubated with the specific inhibitor of the Ubc13-Uev1A complex NSC697923, in the indicated conditions before D-glucose was added. The results represent 4 independent experiments. $B, C) \mathrm{HG}$ effect on $\beta$-actin Lys63 ubiquitination. $B$ ) $\beta$-Actin Lys63 ubiquitination was analyzed by immunoprecipitation of total protein lysates, with a specific anti- $\beta$-actin antibody and subsequent Western blot analysis with an anti-ubiquitin, Lys63-specific antibody (top). The same membrane was then stripped and blotted again with anti- $\beta$-actin antibody (bottom). siUBE: UBE2v1 silencing for the indicated time periods. Scramble: vital scrambled control. Results are representative of 3 experiments. C) Quantification of specifically Lys63-ubiquitinated $\beta$-actin, compared with the total amount of $\beta$-actin. Histogram data are means \pm SD. ${ }^{\circ} \mathrm{P}<0.05 \mathrm{HG} 48 \mathrm{~h}$ vs. basal; ${ }^{\S} \mathrm{P}<0.05 \mathrm{HG}+\operatorname{siUBE} 48 \mathrm{~h}$ vs. HG $48 \mathrm{~h} ; * P=0.05 \mathrm{HG} 48 \mathrm{~h}$ vs. LG $48 \mathrm{~h}$.

UBE2v1; 4) kidneys from patients with diabetes showed an upregulation of both UBE2v1 expression and Lys63 protein ubiquitination that was further increased in patients with DN at the tubular level; 5) the extent of interstitial fibrosis in vivo in patients with DN inversely correlated with the presence of tubular cells charactered by accumulation of Lys63 ubiquitinated proteins and expression of the mesenchymal marker $\alpha$-SMA; and 6) HGinduced $\alpha$-SMA expression in HK2 cells in vitro is linked to Lys63 protein ubiquitination, given that UBE2v1 silencing restored HG-induced $a-S M A$ expression to basal levels.

The role of ubiquitination in DN has been emerging in the past few years (30). Ubiquitination is a complex posttranslational modification responsible for several regulatory functions (16). The modulation of ubiquitin-induced protein degradation in DN has been described and seems to play a role in disease progression $(11,31)$. Lys63 proteinubiquitination instead, has mainly been associated with nonproteolytic regulation of signaling pathways (32), and its involvement in the progression of renal damage induced by HG had never been explored so far.

HG is recognized as a leading cause of diabetic tissue damage (33). In our study, HG elicited a significant increase in Lys63 protein ubiquitination in cultured tubular cells. By a proteomic approach, we identified 30 Lys63-ubiquitinated proteins during HG in tubular cells, each potentially able to play a specific role in the progression of tubular damage in DN. In particular, among these proteins, we identified $\beta$-actin and G1-actin as included in the principal molecular and cellular functions representative of the Lys63ubiquitinated proteins under HG-conditions and observed that Lys63 ubiquitination led to actin disassembly in vitro.

Cytoskeletal disassembly has already been described as an important consequence of high glucose exposure, thus suggesting its contribution in the mechanisms involved in injury progression in $\mathrm{DN}(34,35)$.

These morphologic changes may also predispose patients with diabetes to the development of tubular-interstitial damage (5) and to the progression of fibrosis, which has been described as important as the degree of glomerular sclerosis in the progression of diabetic kidney disease (36).

The involvement of ubiquitination in the organization of cytoskeletal proteins has been recently linked to the proteasome activity (37), whereas the role of Lys63 ubiquitination in the regulation of cellular adhesion and migration has been described only in tumor cells (38). 

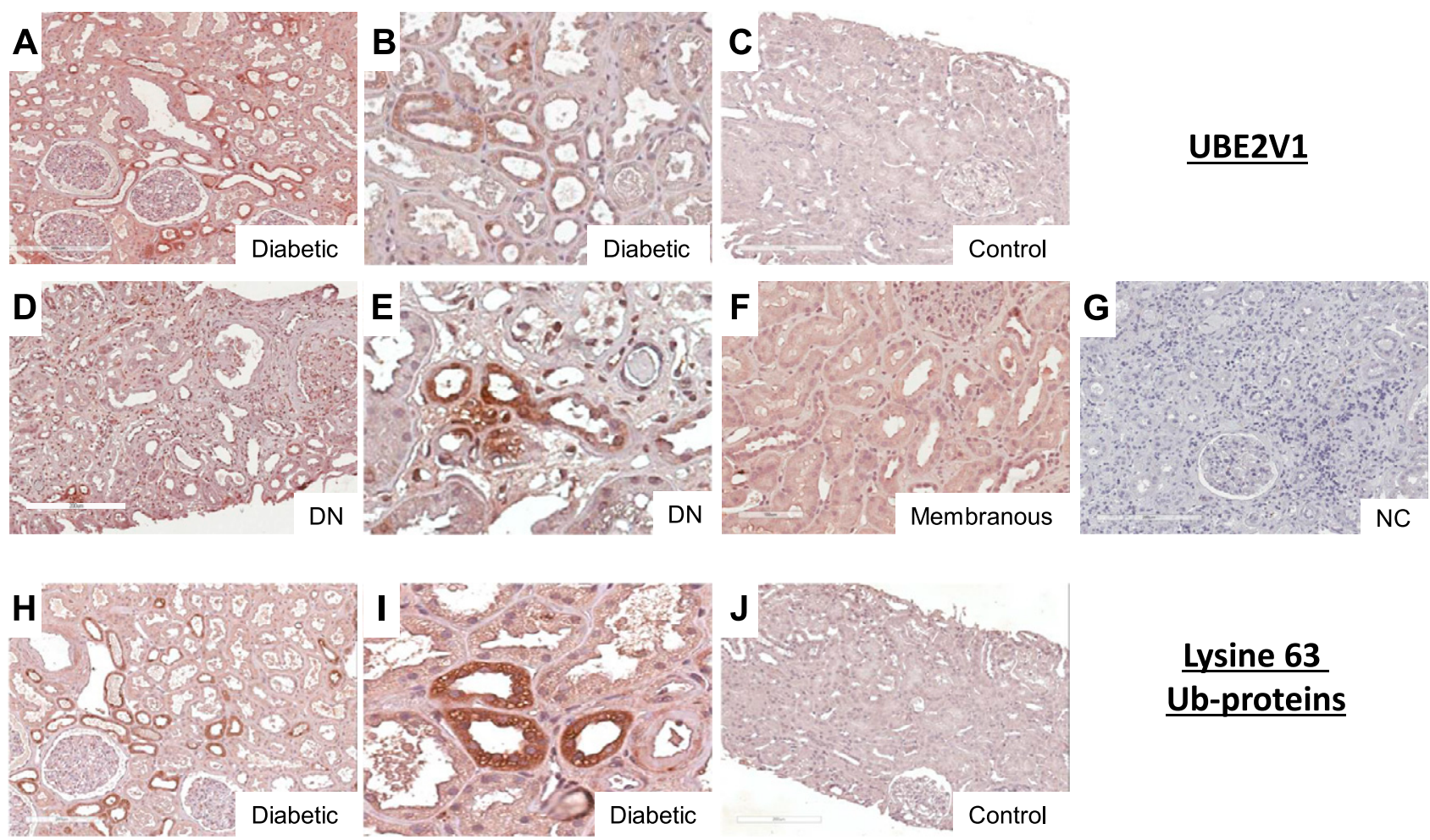

\section{Lysine 63 \\ Ub-proteins}
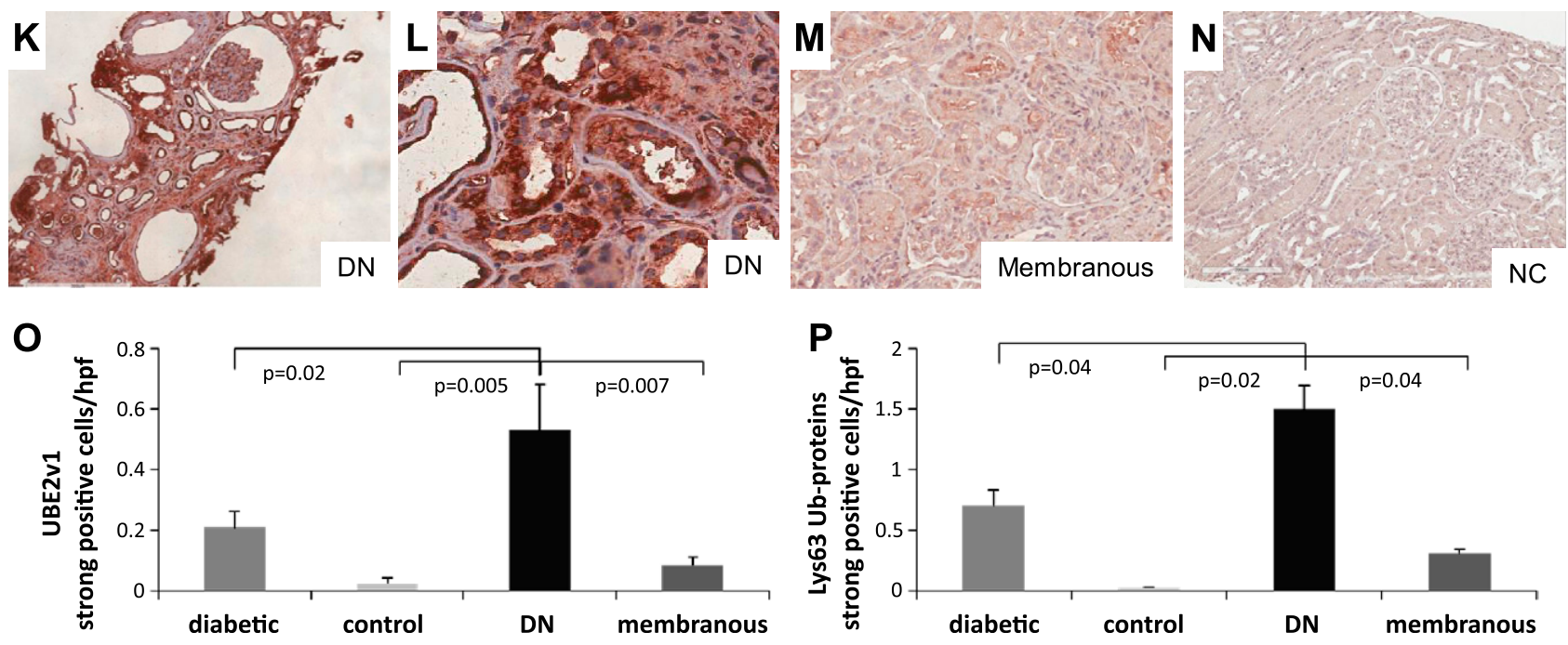

Figure 5. $A-N)$ UBE2v1 protein expression $(A-F)$ and Lys63 protein ubiquitination $(H-M)$ in vivo. Immunohistochemical analysis was performed on kidney biopsies of patients with T2D without (diabetic; $A, B, H, I)$ and with $\mathrm{DN}(D, E, K, L)$ compared to controls $(C, J)$ and membranous nephropathy (membranous; $F, M)$. Negative controls $(\mathrm{NC})$ for UBE2v1 $(G)$ and Lys36 $(N)$ were included. $O, P$ ) Quantification of specific staining for UBE2v1 $(O)$ and Lys36 $(P)$. Data are means \pm SD.

Post-translational modifications, such as $\mathrm{O}$-linked $\mathrm{N}$ acetyl- $\beta$-D-glucosamine modification, have been described as responsible for morphologic changes at both the glomerular and tubular levels in the diabetic kidney, and these modifications involve cytoskeletal proteins (39). Cytoskeletal changes, in turn, would affect the barrier to protein filtration, as suggested by both in vitro studies under HG conditions (40) and in vivo studies in human DN (41). Moreover, actin depolymerization has been described in pancreatic $\beta$ cells after HG exposure, affecting cell survival and function and reducing cell-cell adhesion (42). In line with these data, we observed that HG induced a disassembly of actin fibers in tubular cells through Lys63 protein ubiquitination, since this process was reversed with a specific inhibitor of UBE2v1 complex, NSC697923, which restored actin organization.

In vivo, we observed that UBE2v1 protein expression and Lys63 ubiquitination involve only tubular cells, but not all tubules show the accumulation of Lys63-ubiquitinated proteins. Because the process is already visible in kidney biopsies of patients with T2D and without apparent renal disease, but is almost absent in kidney biopsies from patients with other proteinuric nondiabetic kidney diseases such as $\mathrm{MN}$, we can speculate that those tubules showing an accumulation of Lys63-ubiquitinated proteins could move along a functional and structural change, dependent on 
A

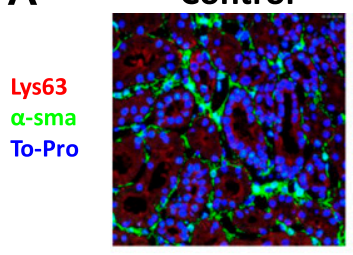

B

ys63

$\alpha$-sma

To-Pro
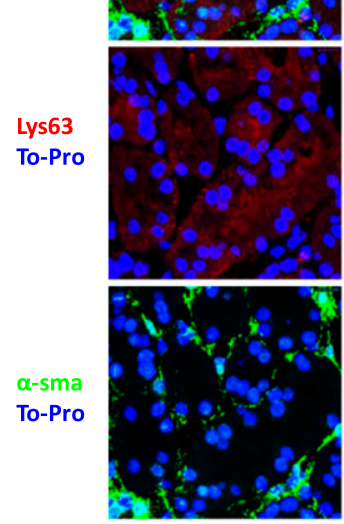

C
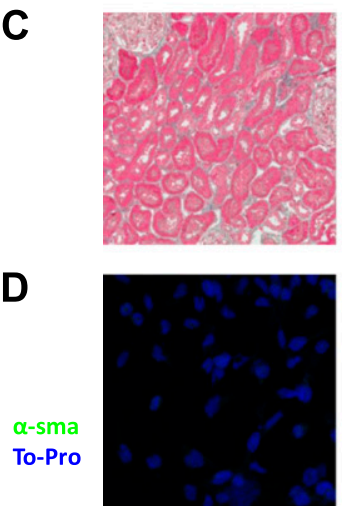

CN
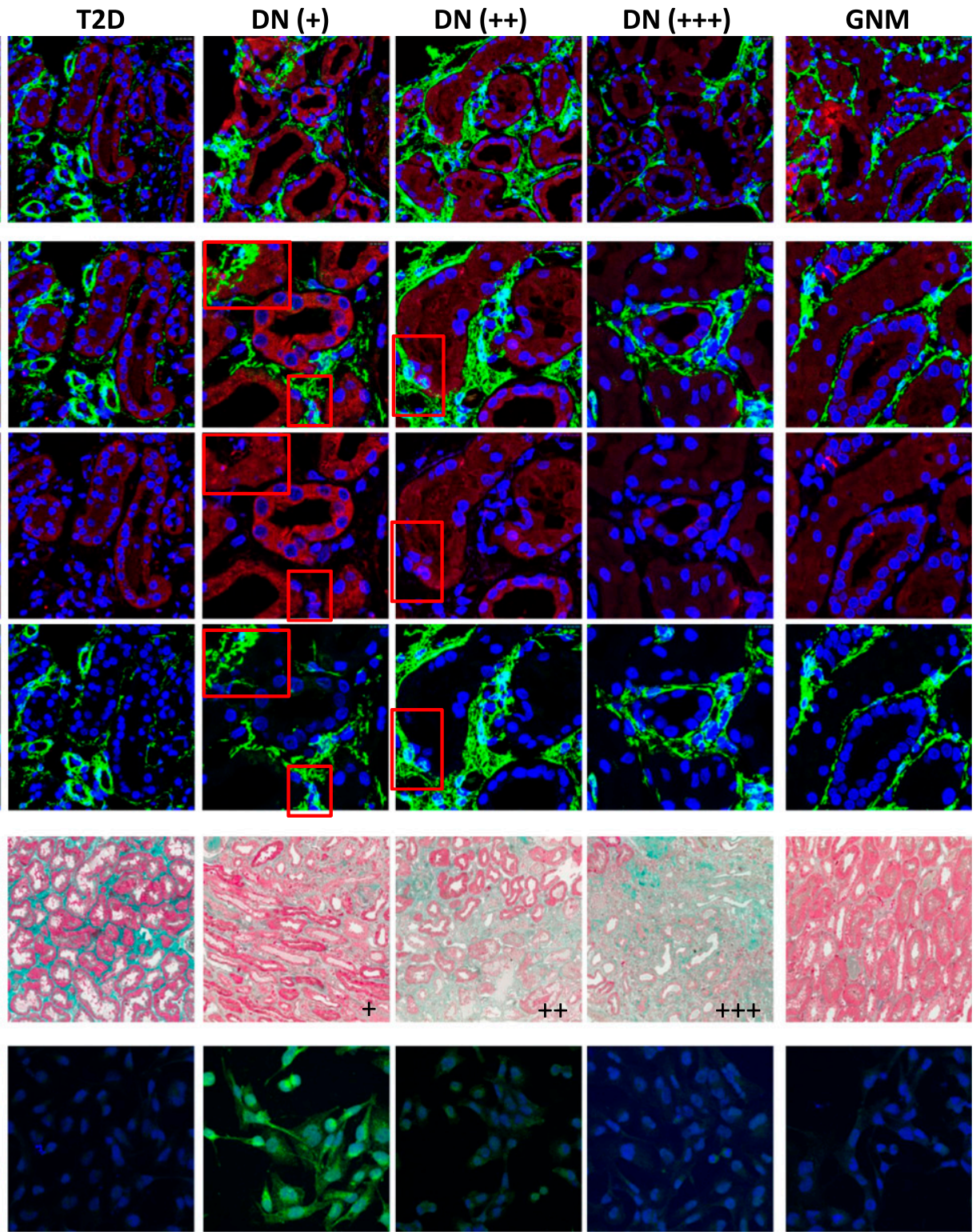

Basal

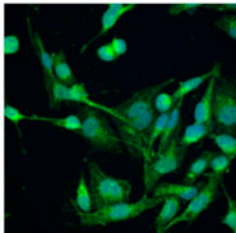

HG 48h

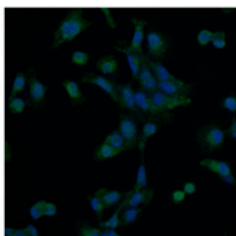

HG48h+

NSC697923

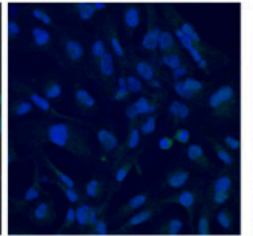

LG 48h

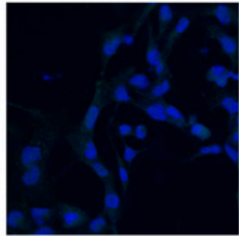

NSC697923
E

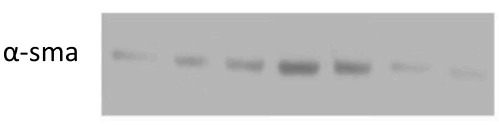

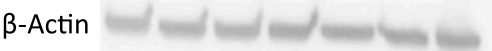

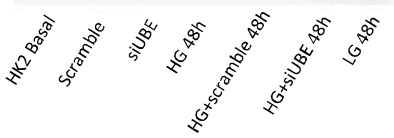

$\mathbf{F}$

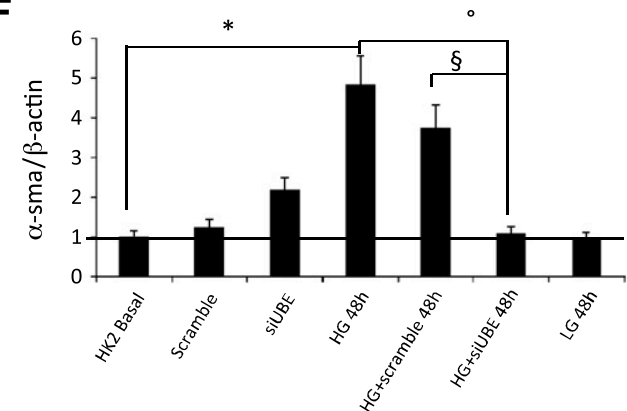

Figure 6. Lys63 ubiquitination and $\alpha$-SMA expression in vivo and in vitro in tubular cells. $A, B)$ Immunofluorescence was performed on kidney biopsies of patients with T2D or without and with diabetic nephropathy (DN) compared to controls and GNM. Original magnification, $\times 63(A)$, and zoom of particular areas $(B)$. $C$ ) Patients with DN were divided in accordance with the range of interstitial fibrosis (+: 0-30\%; ++: 30-60\%; +++: 60-100\%), as determined by Masson's trichrome. $D)$ Immunofluorescence analysis of $\alpha$-SMA expression. Cells were preincubated with the specific inhibitor of the Ubc13-Uev1A complex NSC697923 in the indicated conditions before D-glucose was added (HG). E) $\alpha$-SMA protein levels in HK2 cells (representative of 3 independent experiments) normalized to $\beta$-actin expression. siUBE, UBE2v1 silencing; scramble, vital scrambled control. $F$ ) Quantification of $\alpha$-SMA protein levels normalized to $\beta$-actin expression. Histogram data are means $\pm \mathrm{SD}$. $* P<0.02 \mathrm{HG} 48 \mathrm{~h} v s$. basal; ${ }^{\circ} P<0.05$ HG $48 \mathrm{~h}$ vs. HG+siUBE $48 \mathrm{~h} ;{ }^{\S} P<0.05 \mathrm{HG}+$ scramble $48 \mathrm{~h}$ vs. HG+siUBE $48 \mathrm{~h}$. 
cytoskeletal disassembly, ultimately leading to the onset and progression of overt renal damage. In particular, we also demonstrated that Lys63-ubiquitinated proteins are responsible for increased expression of $\alpha$-SMA, a mesenchymal marker expressed by epithelial cells during EMT. The role of EMT as a source of myofibroblasts and in progression of fibrosis is an open debate (43). Although in vitro studies support the existence of EMT, evidence that fibroblasts derive from epithelial cells in vivo is controversial (44, 45). However, recently Zhao et al. (46) have reported both in vitro in tubular cells after high glucose treatment and in vivo in diabetic rats, the increase in mesenchymal markers (fibronectin, collagen-1, $\alpha$-SMA, and fibroblast-specific protein-1) and the decrease in epithelial markers (E-cadherin and zonula occludens-1), thus concluding that HG plays an important role in EMT and in DN dysfunction. In addition, cytoskeletal alterations have been described to play an important role in EMT in breast cancer cells (47). Because changes in cell morphology represent the main feature of EMT, we also tried to understand whether Lys63 ubiquitination of cytoskeletal proteins could be involved in this cellular process, thus playing a role in the progression of fibrosis in patients with DN. In cancer cells, it has been reported that differentiation from an epithelial to mesenchymal state is regulated by many transcription factors, whose activation is mediated by a ubiquitination-like process called SUMOylation, which consists in the reversible binding of the small ubiquitin-like modifier peptide (SUMO) to a Lys of the target protein (48). Moreover, ubiquitination is responsible for the modulation of the TGF- $\beta$ signaling activity, one of the pathways mainly involved in the regulation of $\operatorname{EMT}(49,50)$, thus emphasizing the role of post-translational modifications in the regulation of intracellular signaling pathways leading to EMT (51). We also confirmed in vitro that inhibition of Lys63 protein ubiquitination specifically suppressed HG-induced $\alpha$-SMA expression, thus defining the possible role played by this post-translational modification in the expression of one of the mesenchymal markers possibly involved in EMT and subsequently in the progression of tubular-interstitial fibrosis in DN. Also in vivo, we demonstrated that the presence of Lys63-ubiquitinated proteins is associated with the expression of $\alpha$-SMA by tubular cells.

We recognize that our study had some limitations. First, the analysis of Lys63 ubiquitination represents an underestimate of what happens in the cells. In addition to ubiquitinated $\beta$-actin, we identified another 29 likely ubiquitinated proteins but, as represented in Fig. $3 A$, the low separation power of monodimensional SDS-PAGE did not allow identification of all immunoprecipitated proteins by MALDI-TOF-MS/MS analysis, which was able to identify, for each gel band, only the most abundant proteins.

Of note, functional analysis was conducted only on the proteins bound to the cytoskeleton but each of the other identified proteins should be investigated, as well.

Moreover, it remains unclear why in patients with DN, only some tubules are involved in increased UBE2v1 protein expression and subsequent Lys63-ubiquitinated protein accumulation, as well as the mechanisms through which tubular damage evolves in these structures.

In addition, the molecular mechanisms by which Lys63 ubiquitination influences the increased expression of
$\alpha$-SMA by tubular cells remain to be investigated, as well as the effective association between increased $\alpha$-SMA expression under HG conditions and EMT in vivo.

In summary, in the present study we observed that Lys63 ubiquitination is a typical hallmark of $\mathrm{DN}$ in vivo, compared to normal kidneys and patients with T2D and other nondiabetic nephropathies such as MN. The presence of Lys63-ubiquitinated proteins emerges as a novel mechanism responsible for the alteration of cytoskeletal organization and appears to be involved in the progression of tubular-interstitial fibrosis by EMT. Finally, we identified UBE2v1 as the gene driving this post-translational modification, thus representing a novel potential target to reduce the progression of tubular damage and fibrosis in DN. F F

\section{ACKNOWLEDGMENTS}

The authors thank Dr. Chiara Divella and Mr. Vincenzo Gesualdo for excellent technical assistance and Dr. Annamaria Di Palma (all from the University of Bari) for helpful discussions of the histologic findings. This study was supported by Ministero della Salute Ricerca Finalizzata 2009: 245/RF-2009-1470765. The authors declare no conflicts of interest.

\section{AUTHOR CONTRIBUTIONS}

P. Pontrelli planned the research, designed and performed most of the experiments, analyzed the respective data, and drafted the manuscript; F. Conserva, A. Oranger, and M. Barozzino performed Western blot experiments and immunohistochemical staining; M. Papale, G. Vocino, and M. T. Rocchetti performed identification of Lys63-ubiquitinated proteins by MALDI-TOF/MS-MS; M. Gigante helped to revise the manuscript; G. Castellano, M. Rossini, and S. Simone enrolled the patients; L. Laviola, F. Giorgino, G. Grandaliano, and S. Di Paolo provided new analytic tools, participated in the design of the study, and critically revised the manuscript; L. Gesualdo planned and supervised the research and drafted the manuscript; and all authors read and approved the final manuscript.

\section{REFERENCES}

1. Soldatos, G., and Cooper, M. E. (2008) Diabetic nephropathy: important pathophysiologic mechanisms. Diabetes Res. Clin. Pract. 82 (Suppl 1), S75-S79

2. Tang, S. C., Leung, J. C., and Lai, K. N. (2011) Diabetic tubulopathy: an emerging entity. Contrib. Nephrol. 170, 124-134

3. $\mathrm{Hu}, \mathrm{C}$. (2015) Insights into the mechanisms involved in the expression and regulation of extraxcellular matrix proteins in diabetic nephropathy. Curr. Med. Chem. 22, 2858-70

4. Liu, Y. (2004) Epithelial to mesenchymal transition in renal fibrogenesis: pathologic significance, molecular mechanism, and therapeutic intervention. J. Am. Soc. Nephrol. 15, 1-12

5. Loeffler, I., and Wolf, G. (2015) Epithelial-to-mesenchymal transition in diabetic nephropathy: fact or fiction? Cells 4, 631-652

6. Yamagishi, S., Fukami, K., Ueda, S., and Okuda, S. (2007) Molecular mechanisms of diabetic nephropathy and its therapeutic intervention. Curr. Drug Targets 8, 952-959

7. Navarro-González, J. F., Mora-Fernández, C., Muros de Fuentes, M., and García-Pérez, J. (2011) Inflammatory molecules and pathways in the pathogenesis of diabetic nephropathy. Nat. Rev. Nephrol. 7, 327-340

8. Sengupta, U., Ukil, S., Dimitrova, N., and Agrawal, S. (2009) Expressionbased network biology identifies alteration in key regulatory pathways 
of type 2 diabetes and associated risk/complications. PLoS One 4 , e8100

9. Woroniecka, K. I., Park, A. S., Mohtat, D., Thomas, D. B., Pullman, J. M., and Susztak, K. (2011) Transcriptome analysis of human diabetic kidney disease. Diabetes 60, 2354-2369

10. Aghdam, S. Y., Gurel, Z., Ghaffarieh, A., Sorenson, C. M., and Sheibani, N. (2013) High glucose and diabetes modulate cellular proteasome function: implications in the pathogenesis of diabetes complications. Biochem. Biophys. Res. Commun. 432,339-344

11. Gao, C., Huang, W., Kanasaki, K., and Xu, Y. (2014) The role of ubiquitination and sumoylation in diabetic nephropathy. BioMed Res. Int. 2014, 160692

12. Cybulsky, A. V. (2013) The intersecting roles of endoplasmic reticulum stress, ubiquitin-proteasome system, and autophagy in the pathogenesis of proteinuric kidney disease. Kidney Int. 84, 25-33

13. Papale, M., Di Paolo, S., Magistroni, R., Lamacchia, O., Di Palma, A. M., De Mattia, A., Rocchetti, M. T., Furci, L., Pasquali, S., De Cosmo, S., Cignarelli, M., and Gesualdo, L. (2010) Urine proteome analysis may allow noninvasive differential diagnosis of diabetic nephropathy. Diabetes Care 33, 2409-2415

14. Dihazi, H., Müller, G. A., Lindner, S., Meyer, M., Asif, A. R., Oellerich, M., and Strutz, F. (2007) Characterization of diabetic nephropathy by urinary proteomic analysis: identification of a processed ubiquitin form as a differentially excreted protein in diabetic nephropathy patients. Clin. Chem. 53, 1636-1645

15. Sun, L., Pan, X., Wada, J., Haas, C. S., Wuthrich, R. P., Danesh, F. R., Chugh, S. S., and Kanwar, Y. S. (2002) Isolation and functional analysis of mouse UbA52 gene and its relevance to diabetic nephropathy. J. Biol. Chem. 277, 29953-29962

16. Xu, G., and Jaffrey, S. R. (2011) The new landscape of protein ubiquitination. Nat. Biotechnol. 29, 1098-1100

17. Neutzner, M., and Neutzner, A. (2012) Enzymes of ubiquitination and deubiquitination. Essays Biochem. 52, 37-50

18. Sadowski, M., and Sarcevic, B. (2010) Mechanisms of mono-and polyubiquitination: ubiquitination specificity depends on compatibility between the E2 catalytic core and amino acid residues proximal to the lysine. Cell Division 5, 19-26

19. Li, W., and Ye, Y. (2008) Polyubiquitin chains: functions, structures, and mechanisms. Cell. Mol. Life Sci. 65, 2397-2406

20. van Wijk, S. J. L., and Timmers, H. T. M. (2010) The family of ubiquitin-conjugating enzymes (E2s): deciding between life and death of proteins. FASEB J. 24, 981-993

21. Komander, D., and Rape, M. (2012) The ubiquitin code. Annu. Rev. Biochem. 81, 203-229

22. Deng, L., Wang, C., Spencer, E., Yang, L., Braun, A., You, J., Slaughter, C., Pickart, C., and Chen, Z.J. (2000) Activation of the IkappaB kinase complex by TRAF6 requires a dimeric ubiquitin-conjugating enzyme complex and a unique polyubiquitin chain. Cell 103, 351-361

23. Petroski, M. D., Zhou, X., Dong, G., Daniel-Issakani, S., Payan, D. G., and Huang, J. (2007) Substrate modification with lysine 63-linked ubiquitin chains through the UBC13-UEVIA ubiquitin-conjugating enzyme. J. Biol. Chem. 282, 29936-29945

24. Hale, P. J., López-Yunez, A. M., and Chen, J. Y. (2012) Genome-wide meta-analysis of genetic susceptible genes for Type 2 Diabetes. $B M C$ Syst. Biol. 6(Suppl 3), S16

25. Pulvino, M., Liang, Y., Oleksyn, D., DeRan, M., Van Pelt, E., Shapiro, J., Sanz, I., Chen, L., and Zhao, J. (2012) Inhibition of proliferation and survival of diffuse large B-cell lymphoma cells by a small-molecule inhibitor of the ubiquitin-conjugating enzyme Ubc13-Uev1A. Blood 120, 1668-1677

26. Ryan, M.J., Johnson, G., Kirk, J., Fuerstenberg, S. M., Zager, R. A., and Torok-Storb, B. (1994) HK-2: an immortalized proximal tubule epithelial cell line from normal adult human kidney. Kidney Int. 45, 48-57

27. Rocchetti, M. T., Papale, M., d'Apollo, A. M., Suriano, I. V., Di Palma, A. M., Vocino, G., Montemurno, E., Varraso, L., Grandaliano, G., Di Paolo, S., and Gesualdo, L. (2013) Association of urinary laminin G-like 3 and free $\mathrm{K}$ light chains with disease activity and histological injury in IgA nephropathy. Clin. J. Am. Soc. Nephrol. 8, 1115-1125

28. Xu, G., Paige, J. S., and Jaffrey, S. R. (2010) Global analysis of lysine ubiquitination by ubiquitin remnant immunoaffinity profiling. Nat. Biotechnol. 28, 868-873

29. Renal Pathology Society. (2010) Pathologic classification of diabetic nephropathy. J. Am. Soc. Nephrol. 21, 556-563

30. Luo, Z. F., Qi, W., Feng, B., Mu, J., Zeng, W., Guo, Y. H., Pang, Q., Ye, Z. L., Liu, L., and Yuan, F. H. (2011) Prevention of diabetic nephropathy in rats through enhanced renal antioxidative capacity by inhibition of the proteasome. Life Sci. 88, 512-520
31. Aghdam, S. Y., Gurel, Z., Ghaffarieh, A., Sorenson, C. M., and Sheibani, N. (2013) High glucose and diabetes modulate cellular proteasome function: Implications in the pathogenesis of diabetes complications. Biochem. Biophys. Res. Commun. 432, 339-344

32. Chen, Z. J., and Sun, L. J. (2009) Nonproteolytic functions of ubiquitin in cell signaling. Mol. Cell 33, 275-286

33. Brownlee, M. (2005) The pathobiology of diabetic complications: a unifying mechanism. Diabetes 54, 1615-1625

34. Dlugosz, J. A., Munk, S., Ispanovic, E., Goldberg, H. J., and Whiteside, C. I. (2002) Mesangial cell filamentous actin disassembly and hypocontractility in high glucose are mediated by PKC-zeta. Am. J. Physiol. Renal Physiol. 282, F151-F163

35. Clarkson, M. R., Murphy, M., Gupta, S., Lambe, T., Mackenzie, H. S., Godson, C., Martin, F., and Brady, H. R. (2002) High glucose-altered gene expression in mesangial cells. Actin-regulatory protein gene expression is triggered by oxidative stress and cytoskeletal disassembly. J. Biol. Chem. 277, 9707-9712

36. Gilbert, R. E., and Cooper, M. E. (1999) The tubulointerstitium in progressive diabetic kidney disease: more than an aftermath of glomerular injury? Kidney Int. 56, 1627-1637

37. Schaefer, A., Nethe, M., and Hordijk, P. L. (2012) Ubiquitin links to cytoskeletal dynamics, cell adhesion and migration. Biochem. J. 442, $13-25$

38. Ray, D. M., Rogers, B. A., Sunman, J. A., Akiyama, S. K., Olden, K., and Roberts, J. D. (2010) Lysine 63-linked ubiquitination is important for arachidonic acid-induced cellular adhesion and migration. Biochem. Cell Biol. 88, 947-956

39. Akimoto, Y., Miura, Y., Toda, T., Wolfert, M. A., Wells, L., Boons, G. J., Hart, G. W., Endo, T., and Kawakami, H. (2011) Morphological changes in diabetic kidney are associated with increased O-GlcNAcylation of cytoskeletal proteins including $\alpha$-actinin 4 . Clin. Proteomics 8, 15-24

40. Ha, T. S. (2006) High glucose and advanced glycosylated endproducts affect the expression of alpha-actinin-4 in glomerular epithelial cells. Nephrology (Carlton) 11, 435-441

41. Kimura, M., Toyoda, M., Kato, M., Kobayashi, K., Abe, M., Kobayashi, T., Miyauchi, M., Yamamoto, N., Umezono, T., and Suzuki, D. (2008) Expression of alpha-actinin-4 in human diabetic nephropathy. Intern. Med. 47, 1099-1106

42. Yeo, R. W., Yang, K., Li, G., and Lim, S. K. (2012) High glucose predisposes gene expression and ERK phosphorylation to apoptosis and impaired glucose-stimulated insulin secretion via the cytoskeleton. PLoS One 7, e44988

43. Zeisberg, M., and Duffield, J. S. (2010) Resolved: EMT produces fibroblasts in the kidney. J. Am. Soc. Nephrol. 21, 1247-1253

44. Humphreys, B. D., Lin, S. L., Kobayashi, A., Hudson, T. E., Nowlin, B. T., Bonventre, J. V., Valerius, M. T., McMahon, A. P., and Duffield, J. S. (2010) Fate tracing reveals the pericyte and not epithelial origin of myofibroblasts in kidney fibrosis. Am. J. Pathol. 176, 85-97

45. Koesters, R., Kaissling, B., Lehir, M., Picard, N., Theilig, F., Gebhardt, R., Glick, A. B., Hähnel, B., Hosser, H., Gröne, H. J., and Kriz, W. (2010) Tubular overexpression of transforming growth factor-betal induces autophagy and fibrosis but not mesenchymal transition of renal epithelial cells. Am. J. Pathol. 177, 632-643

46. Zhao L., Chi L, Zhao J, Wang X, Chen Z, Meng L, Liu G, Guan G, and Wang F. (2016) Serum response factor provokes epithelialmesenchymal transition in renal tubular epithelial cells of diabetic nephropathy. Physiol. Genomics 48, 580-588

47. Chen, Z. Y., Wang, P. W., Shieh, D. B., Chiu, K. Y., and Liou, Y. M. (2015) Involvement of gelsolin in TGF-beta 1 induced epithelial to mesenchymal transition in breast cancer cells. J. Biomed. Sci. 22, 90

48. Bogachek, M. V., De Andrade, J. P., and Weigel, R. J. (2015) Regulation of epithelial-mesenchymal transition through SUMOylation of transcription factors. Cancer Res. 75, 11-15

49. Soond, S. M., and Chantry, A. (2011) How ubiquitination regulates the TGF- $\beta$ signalling pathway: new insights and new players: new isoforms of ubiquitin-activating enzymes in the E1-E3 families join the game. BioEssays 33, 749-758

50. Park, S. H., Jung, E. H., Kim, G. Y., Kim, B. C., Lim, J. H., and Woo, C. H. (2015) Itch E3 ubiquitin ligase positively regulates TGF- $\beta$ signaling to EMT via Smad7 ubiquitination. Mol. Cells 38, 20-25

51. Voutsadakis, I. A. (2012) The ubiquitin-proteasome system and signal transduction pathways regulating epithelial mesenchymal transition of cancer. J. Biomed. Sci. 19, 67

Received for publication February 22, 2016. Accepted for publication September 28, 2016. 


\section{THE}

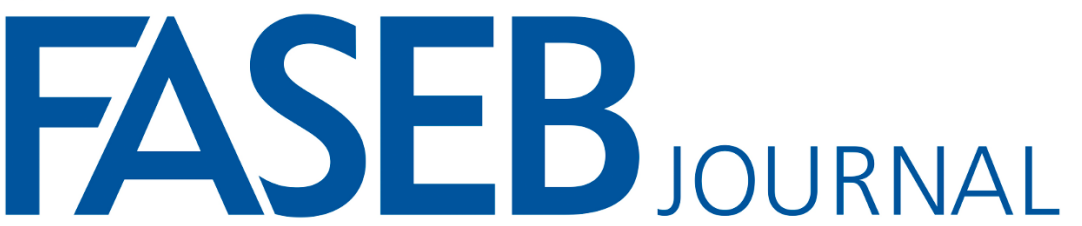

The Journal of the Federation of American Societies for Experimental Biology

\section{Lysine 63 ubiquitination is involved in the progression of tubular damage in diabetic nephropathy}

Paola Pontrelli, Francesca Conserva, Massimo Papale, et al.

FASEB J 2017 31: 308-319 originally published online October 24, 2016

Access the most recent version at doi:10.1096/fj.201600382RR

References This article cites 50 articles, 18 of which can be accessed free at: http://www.fasebj.org/content/31/1/308.full.html\#ref-list-1

Subscriptions Information about subscribing to The FASEB Journal is online at http://www.faseb.org/The-FASEB-Journal/Librarian-s-Resources.aspx

Permissions Submit copyright permission requests at:

http://www.fasebj.org/site/misc/copyright.xhtml

Email Alerts Receive free email alerts when new an article cites this article - sign up at http://www.fasebj.org/cgi/alerts 